\title{
An Enterprise Perspective on Customer Value Propositions for Open Source Software
} Aparna Shanker

\author{
"The single most important thing to remember about" \\ any enterprise is that there are no results inside its \\ walls. The result of a business is a satisfied customer.
}

Peter Drucker (1909-2005)

Professor of business, author, and management consultant

\begin{abstract}
Research on open source software (OSS) has examined value creation primarily from the perspective of the individuals and suppliers that create the software. The perspective of enterprise users who use and pay for OSS has been largely neglected so far. Understanding what paying customers want and how to create products and services they value is the cornerstone of any business model. Therefore, research on what enterprise users value in OSS is of paramount importance to OSS solution suppliers; it can be used to create a new customer base and sustain an existing one.
\end{abstract}

This study examines the value of OSS as perceived by enterprise customers. Through an analysis of three literature streams (firm participation in open source software, business models, and customer value), a model on customer value creation was developed. Interviews were conducted with nine decision makers from enterprises that use OSS in operational projects. The key findings of this research are that: i) the maturity of the software determines the degree to which customers value their relationship with the supplier; ii) customers value differentiating functionality and costs savings; and iii) switching costs with OSS depend on the size, complexity, and dependencies of the software itself. This research identifies the points of value that the suppliers of OSS should focus on, and it points to the need for marketing strategies that can demonstrate this value to enterprise customers.

\section{Introduction}

In the context of open source software (OSS), value creation has been researched from the perspectives of individual users and suppliers. Studies have focused on the factors that motivate individuals and corporations to create and contribute to OSS (e.g., Lerner and Tirole, 2002: tinyurl.com/c64qyft; Dahlander and Magnusson, 2008: tinyurl.com/6w6k95q). Researchers have also focused on the business models that enable companies to generate revenue by selling products and services that are complementary to OSS (e.g., Hecker, 1999: tinyurl.com/ cfxmacm; Krishnamurthy, 2005: tinyurl.com/cyaayyq; Fitzgerald, 2006: tinyurl.com/dxwq3jx).
Although the value of OSS to contributors is now well understood, the literature has little to say about the value of OSS as perceived by customers, particularly enterprise customers. The lack of a price tag on OSS is no doubt attractive to potential customers, even though there may be additional costs in time, money, and manpower incurred when using or maintaining the software. However, the concept of customer value is broader than a simple analysis of costs and monetary value. Customers can also perceive value in higher quality, time savings, ease of use, reduced hassle, and a multitude of other dimensions. The research described in this article addresses the gap in the OSS literature by examining the perception of customer value in all its forms, with an emphasis on enterprise customers. 


\section{An Enterprise Perspective on Customer Value Propositions for Open Source Software} Aparna Shanker

Customers are willing to pay for software and services that produce value for them; so, suppliers need to determine what customers want. Customer value research has typically taken a marketing perspective to understand how customers perceive value and determine what customer would be willing to pay for. There is no marketing research specifically on OSS customers; the research on customer value in the OSS literature focuses on individual users and suppliers. The objective of this research is to analyze how enterprise users perceive value in OSS in an attempt to bridge the gap between the marketing literature and the OSS literature. This research builds on the marketing literature on customer value creation and perception to study how value can be created for enterprise users of OSS.

The deliverables of this research are: i) a list of value points that matter to customers, ii) a model that identifies how value can be created for enterprise users, and iii) a set of propositions and managerial guidelines anchored around the model. The scope of this research is limited to OSS that is used in operational projects and excludes OSS that has been custom made for use in a single enterprise.

There are at least three reasons why research on OSS customers in today's economic environment is relevant. First, entrepreneurs can use the identified points of value as a source of competitive advantage to compete on dimensions other than cost. For example, if cost savings cannot be realized, an entrepreneur could provide better products or service along other dimensions such as quality or customer service. Second, OSS suppliers can conserve valuable resources and capabilities by focusing on the identified points of value that matter to customers, thereby maximizing profits. Third, developing effective customer value propositions can increase customer satisfaction and be used as a means of competitive advantage.

This remainder of this article is organized as follows. The next section describes previous literature on firm participation in OSS, business models, and customer value. Following the literature review, the research method and results are presented. The article concludes with a discussion of the key findings, limitations of the research, and future research directions.

\section{Literature Review}

Three literature streams were selected for the purpose of this research. The first stream is "firm participation in OSS", which identifies the points of value that drive the production of OSS. The second literature stream is "business models", which helps us understand how value creation and value delivery strategies can be employed by a firm. The third literature stream is "customer value"; although the concept of customer value is defined within a business model, an in-depth analysis on value creation and value perception was needed to develop a model on customer value creation. Therefore, the marketing literature pool was studied to better understand these concepts.

\section{Firm participation in OSS}

Firms participate in OSS projects by contributing code, collaborating in code development, providing an OSS product, or integrating OSS components into a software system (Hauge et al., 2010; tinyurl.com/7sdhvjl). Feller and Fitzgerald (2002; tinyurl.com/c9u54hg) identify the economic, social, and political motivations for firms to participate in OSS. The economic motivation of open source is that it allows small to medium-sized enterprises (SMEs) to compete independently from the pricing and licensing policies of large software companies. Moreover, participation in open source projects provides a recruitment ground for firms to find qualified future employees. The social motivation for a firm's participation in OSS projects is sharing the ideology of OSS. Technological motivations include the advantages of levering the intelligence of collectives, obtaining code that is not available in proprietary software, and the quality and reliability of OSS. Morgan and Finnegan (2008; tinyurl.com/bmoj8re) identify the need for firms to participate in an OSS strategy to lower costs and to take advantage of the scalability and reliability of OSS.

\section{Business models}

Among the many definitions of the term business model is the widely cited definition proposed by Magretta (2002; tinyurl.com/cc9bj60): "A business model explains how a company makes money and the economic logic behind it". With a business model for proprietary software, value can be created by producing software that fulfills a customer's need to get a job done. Value is appropriated by methods such as licenses to use the software and patents (if possible). When a firm uses open source assets to satisfy a customer's needs, value must be captured in different ways because the supplier cannot charge for the OSS.

Most open source business models rely on selling complementary goods and services and leveraging other intangible sources such as tacit knowledge over rivals to capture value (West, 2007; tinyurl.com/d5stuaa). There are 


\section{An Enterprise Perspective on Customer Value Propositions for Open Source Software} Aparna Shanker

two main themes in the literature on OSS business models. The first theme focuses on revenue generation and the sale of complementary assets as a means to profit from software that is essentially free (e.g., Hecker, 1999: tinyurl.com/cfxmacm; Krishnamurthy, 2005: tinyurl .com/cyaayyq; Fitzgerald, 2006: tinyurl.com/dxwq3jx; Bonaccorsi et al., 2006: tinyurl.com/7vnupff). The second theme focuses on the concept of value creation, the open source value network, and value capture as a means to profit from OSS (e.g., West and Gallagher, 2006: tinyurl.com/3eb73sq; West, 2007: tinyurl.com/d5stuaa; Morgan and Finnegan, 2008; tinyurl.com/d7bg257).

\section{Customer value}

In a recent article, I reviewed the concept of customer value and how entrepreneurial firms can deliver it (Shanker, 2012a; timreview.ca/article/525). I began with Woodruff's (1997; tinyurl.com/825pdwn) definition of customer value, which is: "a customer perceived preference for and evaluation of those products attributes, attribute performances, and consequences arising from use that facilitate (or block) achieving the customer's goals and purposes in use situations". Thus, as described earlier, the concept of customer value is broader than a simple analysis of costs and monetary value. Beyond price considerations, the term may refer to receiving what is desired, receiving quality for what is paid, or receiving something in return for what is given (Zeithaml, 1988; tinyurl.com/7kjz6nf). The literature identifies the various dimensions of customer value, as shown in Table 1. Value is context-specific, so Table 1 also identifies the context in which each set of value dimensions apply.

A customer value proposition is a firm's pre-emptive value offering that proposes to create value for customers. An effective customer value proposition can attract new customers, increase customer satisfaction, and provide a competitive advantage for the firm (Woodruff, 1997; tinyurl.com/825pdwn). There is no widely accepted framework or methodology for customer value creation and researchers have adopted divergent views on this construct (Sánchez-Fernández and IniestaBonillo, 2007; tinyurl.com/cxwl7vm). At the same time, re-

Table 1. Dimensions of value

\begin{tabular}{|c|c|c|}
\hline Authors & Value dimension & Context \\
\hline $\begin{array}{l}\text { Ulaga } \\
\text { (2003; tinyurl.com/c77vpud) }\end{array}$ & 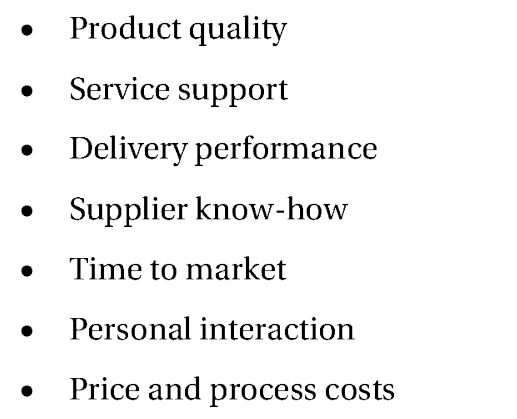 & $\begin{array}{l}\text { - Dimensions of value that apply to } \\
\text { manufacturer-supplier relationships }\end{array}$ \\
\hline $\begin{array}{l}\text { Smith and Colgate } \\
(2007 ; \text { tinyurl.com/75909j3) }\end{array}$ & $\begin{array}{l}\text { - Functional/instrumental value } \\
\text { - Experiential/hedonic value } \\
\text { - Symbolic/expressive value } \\
\text { - Cost/sacrifice value }\end{array}$ & $\begin{array}{l}\text { Marketing managers perspective that } \\
\text { identifies types of value and how an } \\
\text { organization can create these types of } \\
\text { value }\end{array}$ \\
\hline $\begin{array}{l}\text { O'Cass and Ngo } \\
\text { (2011; tinyurl.com/d74rafh) }\end{array}$ & $\begin{array}{l}\text { - Performance value } \\
\text { - Pricing value } \\
\text { - Relationship value } \\
\text { - Co-creation value }\end{array}$ & $\begin{array}{l}\text { Value offerings from a firm's view; } \\
\text { interpretation of what customers are } \\
\text { looking for in the marketplace and what } \\
\text { firms provide in response }\end{array}$ \\
\hline
\end{tabular}




\section{An Enterprise Perspective on Customer Value Propositions for Open Source Software} Aparna Shanker

searchers also acknowledge that understanding the customer value creation strategies applicable to various contexts is central to marketing strategy (Smith and Colgate, 2007; tinyurl.com/75909j3). For this reason, I recently proposed a customer value creation framework specifically for businesses that generate revenue with OSS (Shanker, 2012b; timreview.ca/article/534).

A firm's value creation strategy begins by identifying what points of value to provide to their customers and then developing a pre-emptive plan to provide those benefits (O'Cass and Ngo, 2011; tinyurl.com/d74rafh). A firm's customer value proposition signals the preemptive value that a firm proposes to create for customers. A customer value proposition identifies target customers, the job that the customer needs to have done , and the offering that fulfills the customer's requirements. As far as I am aware, there are only two examples of research on customer value creation with OSS as a key resource: the first is by West (2007; tinyurl.com/d5stuaa) and the second is by Morgan and Finnegan (2008; tinyurl.com/bmoj8re). The value dimensions and context identified by these authors are presented in Table 2.

\section{Lessons Learned and Preliminary Model Development}

The value drivers in OSS creation and use have primarily been studied from the perspective of software producers and individual users. Little is known about how enterprises users value OSS. The literature pool on business models clearly identifies the need for an effective customer value creation and delivery strategy to create a new customer base and sustain an existing one.

The business model literature also identifies a customer value proposition as the cornerstone of any effective business model and the marketing literature identifies the different types of value that can be created for customers. In order to achieve a differentiating advantage, customer value propositions in OSS should focus on features that are unique to OSS.

Figure 1 represents a preliminary model of customer value creation that I developed using the points of value identified in the literature review (Table 1). The preliminary model identifies five types of value and the key attributes of each type of value. (Detailed descriptions of these value types and attributes are provided later, along with the final, refined model.) The value creation strategy outlined in the model shows that a customer value proposition has to be developed and then a firms' value offering has to be refined by re-combining its existing resources and capabilities. The model identifies that customer value perception is constantly evolving and therefore customer value propositions have to evolve to meet changing customer requirements. Further information on the value points identified in the model can be found in my article that describes a customer value creation framework for OSS businesses (Shanker, 2012b; timreview.ca/article/534).

Table 2. Value creation with open source software as a key resource

\begin{tabular}{|c|c|c|}
\hline Authors & Value dimension & Context \\
\hline $\begin{array}{l}\text { Morgan and Finnegan } \\
\text { (2008; tinyurl.com/bmoj8re) }\end{array}$ & 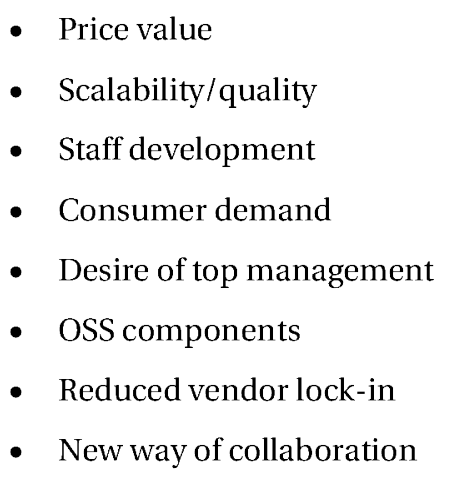 & $\begin{array}{l}\text { - Reasons why firms embrace an OSS } \\
\text { strategy }\end{array}$ \\
\hline $\begin{array}{l}\text { West } \\
\text { (2007; tinyurl.com/d5stuaa) }\end{array}$ & $\begin{array}{l}\text { - Price value } \\
\text { - Less vendor lock-in }\end{array}$ & $\begin{array}{l}\text { Ways in which buyers identified that } \\
\text { OSS created value for them }\end{array}$ \\
\hline
\end{tabular}




\section{An Enterprise Perspective on Customer Value Propositions for Open Source Software} Aparna Shanker

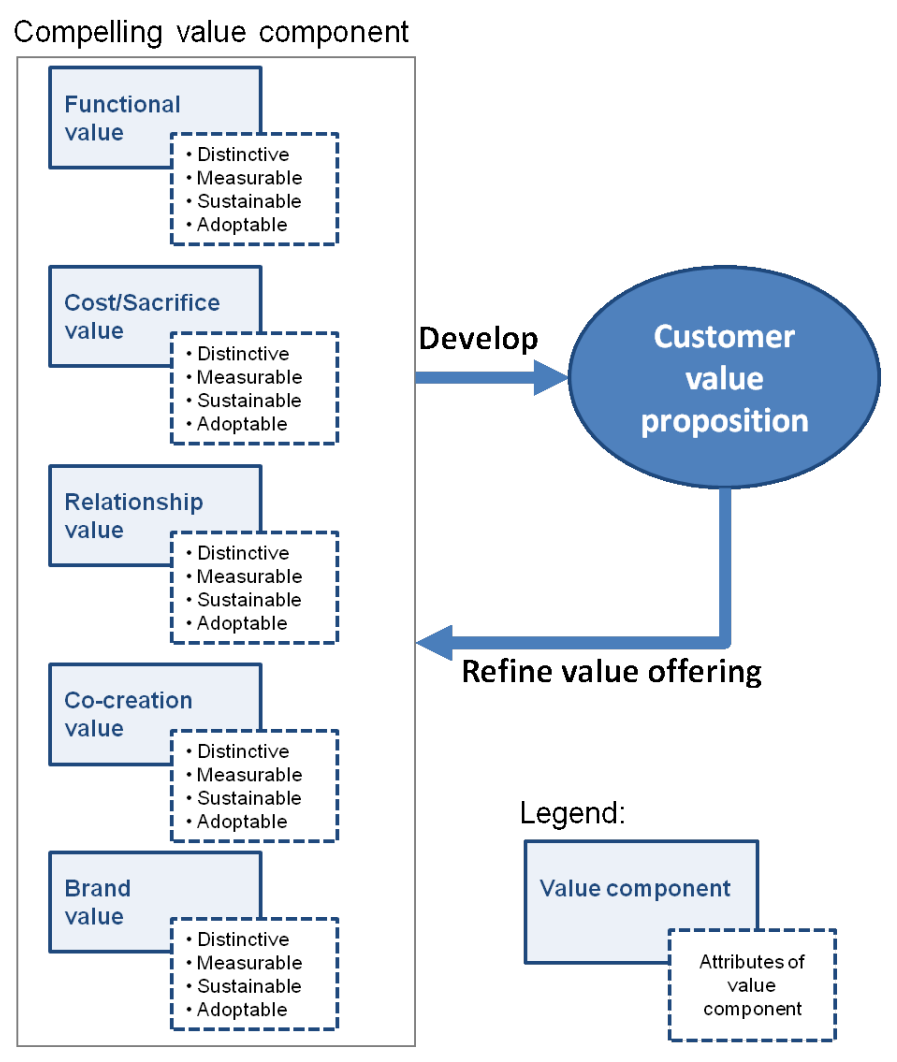

Figure 1. A preliminary model on customer value creation

\section{Research Method}

Once the preliminary model of customer value creation was developed from the literature review, it was refined and validated based on nine semi-structured interviews with managers and leaders of enterprises that use OSS. Interview subjects were presented with the preliminary model and a questionnaire (Box 1), which was developed in consultation with three industry experts.

This approach was chosen because it allowed me to confirm findings across multiple cases (Eisenhardt and Graebner, 2007; tinyurl.com/ckek69c) and to compare and extend emerging patterns across these cases (Yin, 1993; tinyurl.com/caso9gq). The interviewees were split into three groups of cases to increase the probability of developing novel theory by identifying similarities and differences across sets of data (Eisenhardt, 1989; tinyurl.com/7dfuc3z). After completing each set of interviews and analyzing the data, the preliminary model and the questionnaire were refined in an iterative fashion based on the responses from interviewees.
Box 1. Questionnaire presented during interviews with decision makers in enterprises that use open source software

Based on the preliminary model (shown in Figure 1):

1. Rank the five points of value shown in the model in order of importance to you.

2. How do each of the above points create value for you?

3. Are there any other points of value that you would add to the above list?

4. What made you choose an open source solution instead of closed source?

5. Do you think the value creation strategy illustrated in the model would be effective? Why?

6. How do you think the model can be improved?

\section{Model Refinement}

Following three iterations of refinement, the final model was completed (Figure 2). The main differences between the value components identified in the preliminary and the final model were:

1. Relationship value was split into two categories: relationship with the supplier and relationship with the customer. Some of the interview subjects observed that the relationship value component in the preliminary model was too vague. In some cases, there was a relationship with a company, and in other cases, there was a relationship with the OSS community at large.

2. Co-creation value was removed as a value component and added as an attribute of functional value because most customers perceived it as a subset of OSS functionality. They assumed that co-creation was a feature of OSS that was inherent to its functionality.

The attributes of each value component were also modified based on interview data. Initially, each point of value was considered to be distinctive, measurable, sus- 


\section{An Enterprise Perspective on Customer Value Propositions for Open Source Software} Aparna Shanker

tainable, and adoptable. Each value attribute that remained in the final model had been confirmed by more than one customer during the interviews. Any value attribute that was not confirmed by customers, or had its relevance questioned by interview subjects, was removed from the model. New value attributes were added to the model, and remained there, only if they were validated in subsequent interviews.

The final model shown in Figure 2 identifies five key types of value that can be created by OSS solution suppliers and the essential attributes of each value component. These value points and attributes are described below.

\section{Functional value}

There are six key attributes of functional value, which refers to the features of the produce itself:

1. Distinctive: the functionality should be different from other market offers, providing the customer with a differentiating value driver.

2. Sustainable: the functionality and quality should remain the same over time.

3. Extensible: customers should be able to extend the core functionality of the product to interface with their software and services.

4. Customizable: customers should be able to customize a solution to suit their specific needs.

5. Simple: users should be able to understand the functionality of the software with a reasonable amount of effort.

6. Adoptable: the software should be usable in the customer's environment without them having to make major changes to their internal environment.

\section{Cost/sacrifice value}

The product should be worth it to the customer. The cost paid can be in monetary terms, time, effort spend defining requirements, or any other way in which the customer invests in a firm's offering. There are four key attributes of cost/sacrifice value:

1. Distinctive: the sacrifice between "give and get" components for the customer should be less than other alternatives.

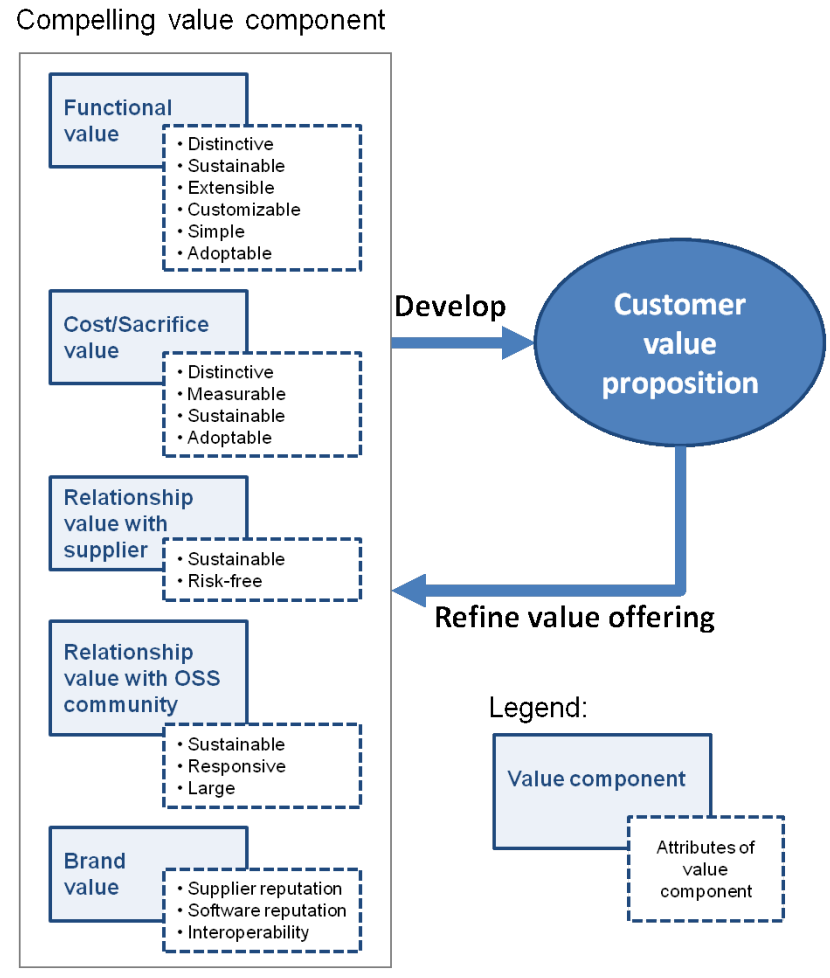

Figure 2. Final model of customer value creation

2. Measurable: there should be significant cost savings for the customer in comparison to other market offers or making the software in-house.

3. Sustainable: the customer should perceive the sacrifice between "give and get" components as being worth it over time.

4. Adoptable: the effort required to overcome barriers to adoption should be perceived as worth it to the customer.

\section{Relationship value to supplier}

This type of value refers to the customer's relationship to an OSS supplier of complementary assets such as customization, consulting, and integration. There are two key attributes of relationship value with suppliers:

1. Sustainable: the supplier should provide the same value to the customer over time by constantly adapting to the customer's requirements. 


\section{An Enterprise Perspective on Customer Value Propositions for Open Source Software} Aparna Shanker

2. Risk-free: the supplier should be able to guarantee a risk-free experience for the customer where support requests are resolved within the timelines required by the customer.

\section{Relationship value to OSS community}

This type of value refers to the customer's relationship to the open source developer community, and it includes their interactions through support forums, developer conferences, and code contributions. There are three key attributes of relationship value to the OSS community:

1. Sustainable: the community activity rate should be sustained over time. If the community becomes less active over time, customers do not perceive the same value from the community.

2. Responsive: the community needs to be responsive to the customer's unique needs.

3. Large: customers perceive the size of the community as a signal for how responsive a community can be and the popularity of the software. A large, well-managed community gives credibility to the community.

\section{Brand value}

The open source brand itself is not important to customers; this is not a factor that motivates them to use OSS, nor is it a value driver for their end-customers. The brand of the software and the supplier are value drivers for customers and there are three key attributes that can be associated with brand value:

1. Supplier reputation: customers trust software that is from a reputable supplier brand that they can trust.

2. Software reputation: customers rely on the online reputation of OSS as their selection criteria.

3. Interoperability: customers consider the interoperability of OSS an advantage, and the open source brand signals the potential for better interoperability with their own hardware and software.

\section{Research Propositions}

Based on the final model presented in Figure 1, the a set of research propositions were developed. These propositions can be tested by future research to determine the strength of the relationship between customer value and the value points identified in the model.
The propositions are:

1A Functional value is increased when OSS provides differentiating functionality that fulfills the customer's exact requirements.

1B Functional value is increased when OSS can be used to reduce time to market.

2 Time and cost savings increase (in comparison to closed source) when customers use OSS in their product offerings.

3A Relationship value to an OSS supplier decreases as OSS product maturity increases.

3B Customer value increases as the size and activity of the OSS community increases.

3C Relationship value increases when suppliers are willing to mitigate risk via a support contract.

4 Customers do not value the OSS brand; they value the reputation of the supplier and the OSS itself.

5A Switching costs increase as the scale of the software deployment expands.

5B Switching costs increase as the number of dependencies in the OSS code increase.

5C Switching costs are low when OSS is used peripherally.

\section{Managerial Guidelines}

Based on the findings of this research, five guidelines were developed for managers and leaders of firms that seek to sell OSS solutions to enterprise users. Firms can use these guidelines to develop an effective customer value delivery strategy. In the interviews conducted during this research, customers confirmed that a value proposition that contains the points of value identified in the model would be part of their software selection criteria. Cost was not always ranked as the most important value driver by customers; functional value was more important to some customers. The five managerial guidelines developed from this research are:

1. A customer value proposition should include differentiating points of value based on the relevant attributes identified in the model. Customers of OSS require support, but the customers that were interviewed for this 


\section{An Enterprise Perspective on Customer Value Propositions for Open Source Software} Aparna Shanker

research did not express satisfaction with the support they received from suppliers or the community. Support contracts that accommodate fast response times and bug fixes are required by customers, and they are currently not available.

2. A customer value proposition should promise faster turnaround times for support with a credible promise to mitigate risk and provide bug fixes. Lower switching costs were only perceived by customers when OSS was used peripherally, in a small scale deployment or when there were few dependencies between software modules.

3. Lower switching costs should only be included in customer value propositions for OSS that is used peripherally, on a small scale or when the software structure is modular. When providing feedback on the model, two interviewees (customers) mentioned that the value creation strategy identified by the model would apply to them, but they usually do not get approached by open source vendors.

4. OSS suppliers should market their abilities to compete with software vendors that sell proprietary solutions. Customers typically seek out the vendors themselves, using the reputation of the software and the supplier as a guide.

\section{OSS suppliers should build their online reputation to} attract customers.

\section{Conclusion}

This research identifies how customer value propositions can be created by firms that use OSS as a key resource. This research subject is unique in at least two ways. First, it contributes to the academic literature on OSS by studying customer value perception from a marketing perspective. Second, it studies enterprise users, whereas most research on OSS to date has studied individual users or OSS suppliers. The findings of this research are also unique because they focus on one type of user: the enterprise. The advantage of focusing on just one specific type of OSS user is that there was no need to generalize the identified types of value to apply to a broad range of customer categories. The applicability of the developed model on a different customer base could be an avenue for future research.

The key conclusions of this research are that a customer's relationship to software suppliers or the open source community depends on four factors: i) the maturity of the OSS; ii) the size and activity of the community; iii) the responsiveness of the supplier in providing support; and iv) the ability of the supplier to manage risks for the customer. Customers value the reputation of the software and supplier; they do not value the OSS ideology itself or the fact that the software they are using is OSS to the same extent. Therefore, suppliers of OSS should focus on managing and marketing their own reputation rather than selling the fact that their product or service is based on OSS. Customers value the functionality of the software; therefore, functionality can be levered as a value driver by suppliers when it is not possible to compete based on cost alone. Customers select OSS based on the reputation of the software and the supplier; they are not approached by OSS vendors. This research identifies the need for marketing strategies that enable open source suppliers to compete with suppliers of proprietary software.

In terms of the limitations of this research, the accuracy of the findings in this research depends on the analysis of data collected from interview subjects and subjective interpretations of these responses. To reduce the risk of inaccurate interpretations, multiple interviews were conducted and all propositions were confirmed in at least two interviews. The results cannot be generalized to a large population or other geographical and cultural settings due to the small set of data derived from a geographically limited area. Both public (universities) and private (for-profit companies) were included in this study and changes in value perception based on the size and profit model of the company were not taken into consideration.

This research identifies the points of value that matter to customers but it is up to the decision makers within a firm to recombine their existing resources and capabilities to deliver value to their customers. Each type of value creation could either be a core competency or a peripheral resource that is already externalized by a firm. Identifying how and when to internalize or externalize the creation and delivery of the five identified value components could be an area for future research.

Further research could also test, validate, and refine the propositions presented. The key question to answer now is: how can these identified points of value be translated into an effective value delivery strategy? 


\title{
An Enterprise Perspective on Customer Value Propositions for Open Source Software
} Aparna Shanker

\begin{abstract}
About the Author
Aparna Shanker is a customer applications engineer with Alcatel-Lucent in Ottawa, where her job focus is on IP networks and the 4G LTE Evolved Packet Core. She is also currently a graduate student in the Technology Innovation Management program at Carleton University. Her research interests include open source businesses and customer value management. She holds an undergraduate degree in Computer Engineering from Queen's University, Kingston.
\end{abstract}

Citation: Shanker, A. 2012. An Enterprise Perspective on Customer Value Propositions for Open Source Software.

Technology Innovation Management Review. December

2012: 28-36. 